\title{
Long term follow up of regnauld's procedure for the treatment of hallux valgus
}

\begin{abstract}
We performed a retrospective study to assess the long-term outcome of regnauld's procedure, as originally described by Regnauld, 1 for the treatment of hallux valgus. This procedure includes the treatment of hallux limitus, hallux rigidus and hallux valgus with associated degenerative joint disease.1,2 In this paper, we have reviewed the long term outcome in terms of the clinical and radiographical results, post-operative quality of life, function of the joint and the late development of osteoarthritis. Between July 1993 and June 1995, 12 patients who had undergone this procedure completed the foot and ankle outcome score survey for the subjective evaluation of symptoms. Clinical re-evaluation, including examination of the foot and the completion of the Maryland Foot Score and American Orthopaedic Foot and Ankle Society questionnaire was performed on 12 patients after a mean follow-up of 14 years. At the final follow-up radiographs of both feet were taken to assess the development of osteoarthritis. The results in terms of foot function and stability did not deteriorate with time and there was little restriction in movement.
\end{abstract}

Keywords: Intermetatarsal, Radiographic, Osteoarthritis, Metatarsophalangeal
Volume I Issue I - 2014

\author{
Fahad Attar, Nagare U,Asirvatham R \\ Department of Orthopaedics, Lincoln County Hospital, United \\ Kingdom
}

Correspondence: Fahad Attar, Department of Orthopaedics, Lincoln County Hospital, Lincoln, LN2 5QY, UK, Tel +44-0 |522573। 5I, Fax +44-0- I522573830,

Email fahadgattar@aol.com

Received: May 20, 2014 | Published: June 22, 2014
Abbreviations: HL, Hallux Limitus; HR, Hallux Rigidus; MTP, Metatarsophalangeal; FAOS, Foot and Ankle Outcome Score; MFS, Maryland Foot Score; AFAS, American Foot and Ankle Score; IMA, Intermetatarsal Angle

\section{Introduction}

Hallux limitus (HL) and hallux rigidus (HR) describe a painful and progressive clinical condition that affects the great toe. The condition is characterised by reduced or absent sagittal plane motion (usually dorsiflexion) of the hallux, with associated degenerative arthritis of the 1st MTP joint. ${ }^{3,4}$ Hallux limitus is generally acknowledged to be a precursor state, before the condition worsens and progresses to hallux rigidus. ${ }^{1,5}$ Both Regnauld 1 \& Hanft et al. ${ }^{2}$ developed widely accepted classification systems for HL, based on either radiographic findings and sub-chondral pathology ${ }^{2}$ or radiographic and clinical changes. ${ }^{1}$ The first MTP joint normally requires 45 to 65 degrees of dorsiflexion for adequate function of foot during ambulation. ${ }^{6}$ The range of motion in the joint will therefore depend on the degree of any occurring arthrosis. In cases of HL, where there is usually only a mild degree of osteophyte formation, there is generally little restriction in the range of motion available. ${ }^{7}$ There has been significant progression of the disease in HR with osteophyte formation and bony hypertrophy and there is a complete absence of motion of the first MTP joint. More than 130 different surgical procedures have been described for its treatment. ${ }^{8}$ The choice of treatment must be decided by individual case. Regnauld developed a procedure using an autogenic osteochondral bone graft in the correction of hallux valgus. ${ }^{1}$ In this paper, we have reviewed our long term clinical and radiographical results of this procedure.

\section{Patients and methods}

We identified 12 patients (12 females), who had undergone a Regnauld's procedure for the treatment of hallux valgus, as described by Regnauld ${ }^{1}$ between July 1993 and June 1995. Those who had moderate or severe degenerative changes (Kellgren grade 3 and 4) were not considered suitable. In 7 patients, the procedure was unilateral and 5 patients had bilateral surgery. All operations were performed by a single orthopaedic surgeon. After mean follow up of 13 years (range 13-15 years), all the patients were assessed clinically and radiographically. The variables studied were clinical data, the time of procedure, complications, the development of OA and objective and subjective function of the foot. The mean age of the patients at operation was 56 years (46-82). Radiographs were made pre and postoperatively, including weight-bearing dosriplantar (AP) and lateral views. Clinical evaluation included a Foot and Ankle Outcome Score (FAOS), Maryland Foot Score (MFS) and American Foot and Ankle Score (AFAS).

Radiographic assessments were made by measurement of the Intermetatarsal Angle (IMA) between the long axes of the first and second metatarsals. The metatarsophalangeal (Hallux valgus) angle was measured by the method of Piggott between the long axis of the first metatarsal and the proximal phalanx. The scale devised by Kellgren and Lawrence (Table 1) was used for grading the degenerative changes involving the first metatarsophalangeal (MTP) joint.

\section{Operative technique}

The procedure was performed under general or spinal anaesthesia with a tourniquet. A direct medial incision was used. The capsule over first MTP joint was divided longitudinally. The proximal third of the proximal phalanx was exposed sub-periosteally. The medial eminence on the first metatarsal head was resected. The proximal one-third of the proximal phalanx was removed and replaced after being fashioned into a 'hat-shaped graft'. The distal part of the proximal phalanx was prepared with a curette and the graft replaced. The sesamoid apparatus was released laterally as described by Du Vries ${ }^{9}$ and repositioned. Medial capsulorrhaphy was performed with a ' $U$ ' shaped stitch. The wound was closed with subcuticular suture and a wool and crape 
bandage, extending between the great and second toe, was applied. Postoperative management included full weight bearing on first postoperative day. The patients were encouraged to stand on tip-toes which should be achieved before 10 days. Hospital stay was 2-3 days. Follow up was 2 weeks, 8 weeks and 6 months.

Table I Grading for radiographic osteoarthritis, based on the Atlas of Standard Radiographs.

$\begin{array}{lll}\text { Grade } & \text { Osteoarthritis } & \text { Radiographic Features } \\ 0 & \text { Absent } & \text { None } \\ \text { I } & \text { Doubtful } & \text { Minute Osteophyte } \\ 2 & \text { Minimal } & \begin{array}{l}\text { Definite osteophyte, minimal } \\ \text { narrowing of joint space }\end{array} \\ 3 & \text { Moderate } & \begin{array}{l}\text { Moderate loss of joint space with } \\ \text { moderate or small osteophyte }\end{array} \\ 4 & \text { Severe } & \begin{array}{l}\text { Severe narrowing of joint space, } \\ \text { subchondral sclerosis, large } \\ \text { osteophyte }\end{array} \\ \end{array}$

\section{Evaluation}

For the subjective evaluation of the outcome the patients filled in FAOS Foot and ankle survey questionnaires. FAOS consists of 5 subscales; Pain, other Symptoms, Function in daily living (ADL), Function in sport and recreation and foot and ankle-related Quality of Life (QOL). The last week is taken into consideration when answering the questionnaire. A normalized score (100 indicating no symptoms and 0 indicating extreme symptoms) is calculated for each subscale. The result can be plotted as an outcome profile. For the objective evaluation of the outcome, the American Orthopaedic Foot and Ankle Society (AOFAS) were used at the final follow-up. The results were graded as excellent (91-100 points), good (81-90 points), fair (71-80 points) and poor ( $<70$ points).

The Maryland foot score was used for clinical assessment at followup (Table 2). This is a validated 24 scoring system ranging from a minimum of 0 to a maximum of 100 (excellent, 90 to 100; good, 75 to 89 ; fair, 50 to 74 ; failure $<50$ ). It evaluates subjective and objective elements such as pain (maximum score 45), function (maximum score 40, subdivided into gait, stability, use of walking aids, limp, type of shoes required, walking distance), cosmesis (maximum score 10) and movement of the ankle, subtalar, midfoot and metatarsophalangeal joints (maximum score 5).

Table 2 Clinical results of the 17 Regnauld procedures according to Maryland foot score

\begin{tabular}{lc}
\hline \multicolumn{2}{l}{ Maryland Foot Score } \\
\hline Excellent & 9 \\
Good & 7 \\
Fair & I \\
Poor & 0 \\
\hline
\end{tabular}

\section{Results}

Of the 20 patients, 12 were available for clinical assessment. Four patients were dead and the remaining four were not able or were unwilling to visit the hospital for clinical re-evaluation. The mean follow-up was 13 years (13 to 15). Ninety five percent of the patients were satisfied with this operation. There was no pain over the first MTP joint, a satisfactory cosmetic result, no complaints about their footwear. Ten patients $(83 \%)$ were able to wear all types of shoes with heels of their choice. The mean total FAOS score was 94.7 (88-100). The mean AOFAS score was 93.7 (87-96). The mean Maryland foot score was 90.8 (78-100). The mean sub scores are presented in Table 1 and 3 .

Table 3 Clinical results of the 17 Regnauld procedures according to American foot and ankle score

\begin{tabular}{lc}
\hline \multicolumn{2}{l}{ American Foot and Ankle Score } \\
\hline Excellent & 10 \\
Good & 6 \\
Fair & 1 \\
Poor & 0 \\
\hline
\end{tabular}

\section{Radiographic results}

The mean Hallux valgus angle preoperatively was $30^{\circ}$ (range 2050). Following surgery, it was a mean of $11.5^{\circ}$ but, at final follow up the mean hallux valgus angle was $18.5^{\circ}$. The mean correction at final follow up was $16.8^{\circ}$. The mean intermetatarsal angle was $15.2^{\circ}$ (range 9-20) preoperatively. At final follow up the mean intermetatarsal angle was $14.3^{\circ}$ (range $8-18$ ). Four patients (35\%) showed progression of osteoarthritis involving the first MTP joint but they were pain-free. There was no displacement or loss of position of the graft or nonunion in any of them. All patients were satisfied with the aesthetic and functional results. No patient reported limitations on duration and distance of walking (Figure 1\&2).

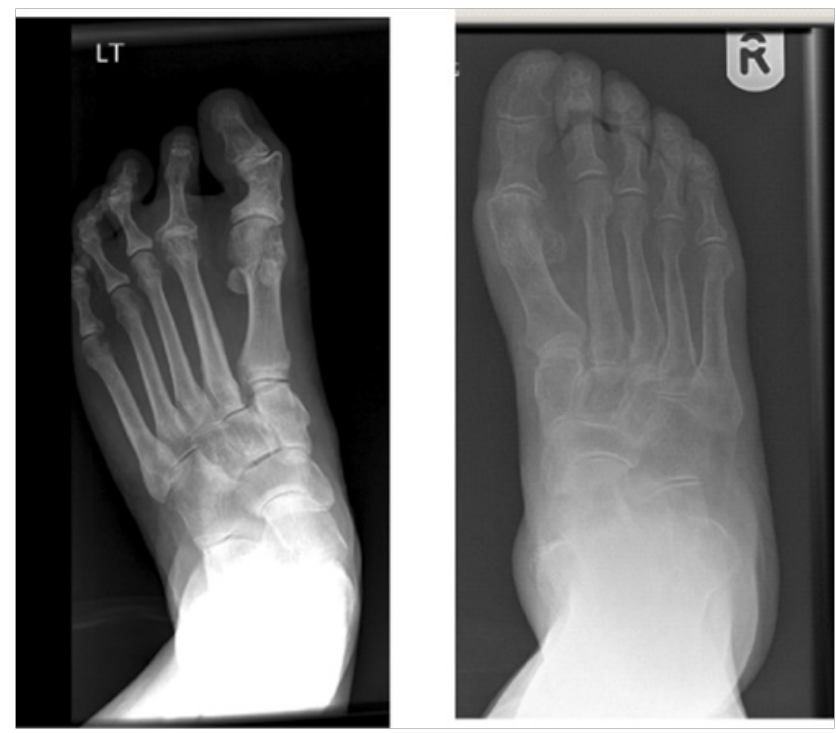

Figure I Radiographs at 13 year follow up. 


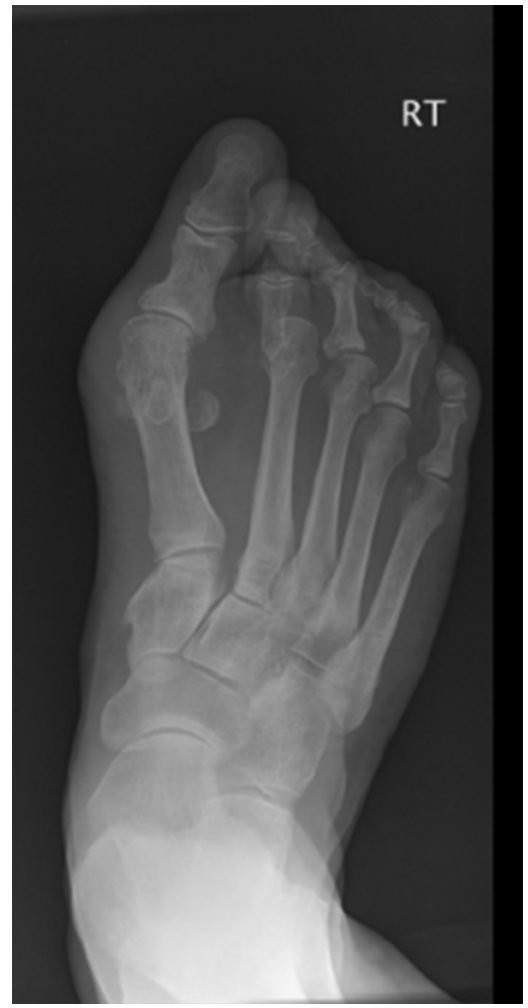

Figure 2 Progression of osteoarthritis.

\section{Discussion}

Hallux valgus is disabling condition and gives significant amount of pain to patient. The goal of treatment is to relieve pain by attempting to restore the normal biomechanical relationship of first ray.10-12 Various surgical procedures include bony procedures, soft tissue realignments or combination of both. The operative options for hallux valgus of first MTP with degenerative disease are arthrodesis, resection arthroplasty and total joint arthroplasty. Complications are associated with each procedure. Regnauld bunionplasty has uncomplicated postoperative regime. No cast is required and full weight bearing is encouraged which leads to minimal swelling, less pain and shortened rehabilitation period. Our 13 years follow up study has achieved the goal of treatment of hallux valgus. It corrects the hallux valgus angle but minimal correction of intermetatarsal angle. Surgical technique is not easy and preparation of graft is difficult in osteoporotic bone.13 There is painless progression of osteoarthritic changes at the first MTP joint.14 Considering high incidence of degenerative changes in the first MTP joint, this procedure is reserved for those patients over the age of 65 years or in those with early osteoarthritic changes in the first MTP joint.

\section{Acknowledgments}

None.

\section{Conflicts of interest}

The author declares that there is no conflict of interest.

\section{References}

1. Regnauld B. The Foot: Pathology, Aetiology, Semiology, Clinical Investigation and Therapy. Springer-Verlag, New York, 1986.

2. Hanft JR, Mason ET, Landsman AS, et al. A new radiographic classification for hallux limitus. J Foot Ankle Surg. 1993;32(4): 397-404.

3. Coughlin MJ, Shurnas PS. Hallux rigidus. Grading and long-term results of operative treatment. J Bone Joint Surg Am. 2003;85-A(11):2072-2088.

4. Coughlin MJ, Shurnas PS. Hallux rigidus: demographics, etiology, and radiographic assessment. Foot Ankle Int. 2003;24(10): 731-743.

5. Bingold AC, Collins DH. Hallux rigidus. J Bone Joint Surg Brr. 1950;32$\mathrm{B}(2): 214-222$.

6. Root ML, Orien WP, Reed JH. Normal and abnormal functions of the foot. In: Clinical biomechanics. Clinical Biomechanics Corp, Los Angeles, 1977.

7. Camasta CA. Hallux limitus and hallux rigidus. Clinical examination, radiographic findings, and natural history. Clin Podiatr Med Surg. $1996 ; 13(3): 423-448$.

8. Kelikian H. Hallux valgus: allied deformities of the forefoot and metatarsalgia. Philadelphia: W B Saunders. British Journal of Surgery. 1965;53(1):83.

9. Rolfsen L. Du Vries' operation for hallux valgus. Nord Med. 1971;85(12):378.

10. Mann RA. Hallux valgus. Instr Course Lect. 1986;35:339-353.

11. Mann RA. Disorders of the first metatarsophalangeal joint. J Am Acad Orthop Surg. 1995;3(1):34-43.

12. Mann RA, Coughlin MJ. Hallux valgus - etiology, anatomy, treatment and surgical considerations. Clin Orthop Relat Res. 1981;(157):31-41.

13. Meyer HR, Muller G. Regnauld procedure for hallux valgus. Foot Ankle. 1990;10(6):299-302.

14. Kurian J, Pack Y, Asirvataham R. Regnauld's procedure for the treatment of hallux valgus. The Foot. 2000;10(4):177-181. 